\section{Archivos de \\ Ciencias \\ Educación}

Archivos de Ciencias de la Educación ISSN: 2346-8866

revistaarchivos@fahce.unlp.edu.ar

Universidad Nacional de La Plata

Argentina

\title{
Paulo Freire y la Igualdad
}

\author{
Kohan, Walter Omar \\ Paulo Freire y la Igualdad \\ Archivos de Ciencias de la Educación, vol. 13, núm. 16, 2019 \\ Universidad Nacional de La Plata, Argentina \\ DOI: https://doi.org/10.24215/23468866e068
}

Atribución no comercial compartir igual (CC BY-NC-SA) 4.0 
Dossier: A 50 años de Pedagogía del Oprimido: lecturas en torno al legado de Paulo Freire

\section{Paulo Freire y la Igualdad}

Paulo Freire and Equality

Walter Omar Kohan

DOI: https://doi.org/10.24215/23468866e068

Universidade do Estado do Rio de Janeiro, Brasil

wokohan@gmail.com

Recepción: 22 Octubre 2019

Aprobación: 29 Noviembre 2019

\section{Resumen:}

Este artículo busca dilucidar el sentido filosófico de la igualdad afirmado por Paulo Freire como una condición de una educación liberadora. En la primera sección, propone un examen detallado y conceptual de la afirmación "nadie es superior y nadie"; en una segunda, considera los significados que este examen proyecta para una vida educativa; estudia el significado de la igualdad en la relación pedagógica; en la siguiente, presenta las ideas de otro defensor de la igualdad, el francés Joseph Jacotot; luego, contrasta los ideales de Jacotot con los de Paulo Freire, destacando los puntos en común y las diferencias tanto en sus vidas como en sus pensamientos educativos; finalmente, presenta algunas conclusiones sobre el valor de la igualdad, inspiradas por la lectura de estos autores, en particular, con respecto a conocer y pensar sobre una educación dirigida a la emancipación.

Palabras ClaVE: Paulo Freire, Igualdad, Joseph Jacotot.

\section{Aвstract:}

This article seeks to elucidate the philosophical sense of equality affirmed by Paulo Freire as a condition of a liberating education. In the first section, a detailed and conceptual examination of the already mentioned phrase; in a second section, the paper considers the meanings that this examination projects to an educational life; it studies the sense of equality in the pedagogical relationship; in a following section, it introduces the ideas of another defender of equality in education, the French Joseph Jacotot; in another section, it compares Jacotot's ideals with those of Paulo Freire, highlighting common aspects and differences, both in their lives and in their educational thoughts; finally, it draws some conclusions about the value of equality, inspired by the reading of these authors, in particular with regard to the place of knowledge and thinking in an emancipatory education.

KEYWORDS: Paulo Freire, Equality, Joseph Jacotot.

\section{INTRODUCCIÓN}

Paulo Freire afirma la igualdad de educadores y educadoras en relación con sus educandas y educandos: "nadie es superior a nadie" (Freire, 2008 [1996], p. 114). La afirmación es presentada como "una de las raras certezas de las que estoy seguro". El contexto de la frase es bastante esclarecedor en cuanto a la importancia de que educadores y educadoras sepan escuchar a educandos y educandas, lo que requiere una escucha atenta, verdadera, una disponibilidad permanente en relación con el otro y una serie de virtudes como amor, respeto, tolerancia, humildad, gusto por la vida, apertura a lo nuevo, entre otras (Freire, 2008 [1996], p. 113).

Paulo Freire argumenta también que una de las condiciones es “aceptar o respetar la diferencia” porque quien considera que su pensamiento es el único correcto no escucha al otro sino que lo desprecia o destrata. Así, según Freire, la humildad es una virtud principal del educador, pues parte del presupuesto de que alguien que se siente superior no escucha a nadie más que a sí mismo. De ese modo, la igualdad implícita en la afirmación "nadie es superior a nadie" resulta una exigencia para una educación emancipadora. Sin embargo, ¿cuál es el alcance de esa exigencia?

La cuestión es compleja. Por un lado, nuestras sociedades viven una desigualdad que se extiende en sus más diversos niveles: económico, político, social, cultural, educativo. La igualdad, en esos niveles, está completamente ausente. Así, no es a esa dimensión de la igualdad a la que Paulo Freire se está refiriendo. ¿Eso 
significa que el pernambucano defendía, como leemos usualmente, una educación que coloca a la igualdad como uno de sus objetivos en la lucha por una sociedad menos desigual? ¿La igualdad sería un fin de la educación exigido por la desigualdad socialmente imperante?

No parece. Ciertamente, la igualdad puede ser un objetivo por alcanzar en algunas esferas, como la económica, la social o la política. No obstante, hay fuertes indicios de que, en otros planos, como el ontológico, Paulo Freire afirmaba la igualdad como principio. Como Carlos Rodrigues Brandão afirma, uno de los postulados fundamentales de la educación en Freire es "la igualdad ontológica de todo los hombres" (Brandão, 2015, p. 172).

En El maestro ignorante, Jacques Rancière rescata al legendario Joseph Jacotot, que, en el siglo XIX, afirmó la igualdad intelectual de los seres humanos como principio de una educación emancipadora del pueblo. En una entrevista publicada un año después del lanzamiento de dicha obra en Brasil, Rancière observa algunas diferencias entre Joseph Jacotot y Paulo Freire, dos defensores de la emancipación: el primero afirma una emancipación intelectual e individual, basada justamente en el principio de igualdad de las inteligencias; mientras que Paulo Freire piensa en una emancipación social. No obstante, sugiere Rancière, esa diferencia se asienta en algo común: "Hay, pues, una distancia entre las intenciones de la emancipación intelectual jacotista y movimientos como el de Paulo Freire. Pero hay algo en común, en el proceso de emancipación intelectual, como vector de movimientos de emancipación política que rompen con una lógica social, una lógica institucional” (Vermeren; Cornu; Benvenuto, 2003). ¿Paulo Freire compartiría, entonces, el axioma de la igualdad de las inteligencias a partir del cual sería buscada la emancipación social?

Esta pregunta parece exigir una respuesta afirmativa: sin esa convicción en la igual capacidad intelectual de los seres humanos, difícil sería poder anhelar una igualdad en los otros planos en que reina, socialmente, la desigualdad. En ese mismo sentido, Lidia Rodríguez $(2007 ; 2015)$ muestra que, en la concepción de educación de Paulo Freire, la igualdad inicial con los descalificados por la educación bancaria es una condición necesaria para su liberación ética y política. En un libro reciente sobre Paulo Freire, Moacir Gadotti y Martin Carnoy (2018, p. 16) afirman, siguiendo a Muniz Sodré, que la emancipación intelectual debe ser entendida como un principio general, y que Paulo Freire la entiende como concientización.

Otro estudioso de Freire, Alípio Casali sugiere que, en el ambiente de contestación antiautoritaria de los años 1970 cuando se publicó Pedagogía del oprimido, esa igualdad era tomada al pie de la letra, en una lectura que define como romántico-anárquico-igualitaria. Argumenta que eso traía problemas de comprensión del papel pedagógico de quien enseña y de quien aprende, pues, "si profesores y alumnos son iguales en el punto de partida de la acción pedagógica, ¿qué es lo que, al final, justifica la educación?” (Casali, 2001, p. 18). Concluye que, después de cierto tiempo, se entendió como una igualdad ético-cívica, condición de la educación, pero sin anular la "indispensable desigualdad epistemológica que, al final, justifica toda acción pedagógica”. También mantiene una desigualdad cultural que justificaría la acción pedagógica. O sea, enseñar encontraría justificación en una cultura y en un saber que el educador tiene y que el educando no tiene, lo que los haría desiguales epistemológicamente.

Con todo, ¿qué significa, entonces, que nadie es superior a nadie? Si esa igualdad no tuviese proyección sobre el campo epistemológico, ¿no correríamos el riesgo de estar propagando, entonces, una desigualdad política - que afectaría la simetría de la relación entre quien enseña y quien aprende? ¿Podríamos, al contrario, mantener la igualdad como principio en ese campo y diferenciar los saberes según otros criterios? ¿Cómo pensar la igualdad en relación con la capacidad cognitiva e intelectual de educadoras y educadores, educandas y educandos? Al final, ¿cuál es la real aplicabilidad, en el campo educativo, de la idea de igualdad?

Son algunas de las preguntas que intentaré tematizar en este texto: primero, con un examen conceptual de la afirmación ya citada "nadie es superior a nadie"; después, con la consideración de los sentidos que ese examen proyecta a la vida educativa; en la sección siguiente, introduciré las ideas del ya mencionado defensor de la igualdad en educación, Joseph Jacotot, para, en una sección posterior, contrastar sus ideas con las de 
Paulo Freire; finalmente, en una última sección, volveré a las cuestiones centrales relativas al valor de la igualdad.

\section{SENTIDOS DE LA IGUALDAD}

Volvamos a la afirmación freireana de que "nadie es superior a nadie". Hagamos un ejercicio de lógica. Hay tres afirmaciones que pueden desprenderse de ella. La primera es igualmente negativa: "Nadie es inferior a nadie". Superior o inferior son términos semánticamente dependientes: si nadie es superior a nadie, necesariamente, nadie es inferior a nadie. Si no hay superiores, necesariamente no hay inferiores. Eso es lo que parece decir Paulo Freire cuando señala las consecuencias negativas que habría si un educador o educadora se considerase superior a sus educandos o educandas. En ese caso, los consideraría inferiores, y nadie dialoga con un inferior, ni con un superior. Solo hay diálogo entre iguales. Por eso, nadie se puede sentir superior (ni inferior) a nadie en una educación dialógica.

La segunda proposición que se desprende de aquella es también negativa - "nadie es desigual a nadie”-, y supone una reunión de las dos anteriores. El concepto "desigualdad" abarca los de superioridad e inferioridad, esto es, la superioridad y la inferioridad son dos formas de desigualdad. Lógicamente, si no hay superiores e inferiores, no puede haber desiguales.

La tercera proposición es afirmativa. Si no hay desiguales, entonces sólo puede haber iguales. Así la tercera proposición que se desprende de aquella primera de Paulo Freire ("Nadie es superior a nadie") es "todos somos iguales". La frase expresa afirmativamente la igualdad, justamente lo que las otras resguardan negando, ya sea la superioridad, la inferioridad, o la reunión de ambas, la desigualdad.

La igualdad no se opone a la diferencia, sino a la desigualdad. Todos podemos ser iguales y diferentes. Lo que no podemos es ser iguales y desiguales, superiores e inferiores. Eso es justamente lo que Paulo Freire parece estar afirmando. Más aún, coloca la diferencia como una condición de la igualdad: si no fuéramos diferentes, no habría necesidad de la igualdad. El concepto de diferencia es lógicamente una condición del concepto de igualdad - sin diferencia, la igualdad sería superflua.

Al contrario, la igualdad no es una condición lógica de la diferencia. Podríamos ser diferentes y desiguales. Sin embargo, la igualdad es una condición política de la diferencia. Sólo entre iguales es posible una afirmación políticamente deseable de la diferencia. Eso parece ser también sugerido por Paulo Freire: sólo quien considera al otro como igual lo afirma como diferente. Paulo Freire relaciona esa afirmación con la diferencia de tratamiento para con otros y otras; por eso, el respeto por el otro es una medida de la consideración del otro como igual.

Podemos desprender de aquella proposición de Paulo Freire - y de las otras que hemos incorporado - que no hay educación liberadora, políticamente justa si educadores y educadoras se ponen por encima de educandas y educandos. Para aquéllos, hay una exigencia política de igualdad: nadie arriba, nadie abajo. Nadie superior, nadie inferior, pues, cuando hay superiores e inferiores, se siguen órdenes, se satisface, se premia, se castiga, se obedece... pero no se piensa junto, no se dialoga, no se escucha con atención. Paulo Freire da el ejemplo de un educador simplista que caricaturiza a sus alumnos de clase popular cuando cambia su lenguaje para "adecuarlo a las posibilidades de comprensión de sus alumnos" (Freire; Shor, 2014 [1986], p. 238). En ese caso, los coloca en un nivel de capacidad inferior, los subestima. En consecuencia, no hay educación políticamente consistente: transmite una jerarquía que es incompatible con una educación liberadora. Sus estudiantes aprenden con él a sentirse inferiores, cuando es justamente de ese sentimiento que precisan liberarse. 


\section{IGUALDAD DENTRO Y FUERA DE LA ESCUELA}

Hemos afirmado, en otro texto (Kohan, 2018), el modo como Paulo Freire reúne la teoría y la práctica, el pensamiento y la vida. En efecto, no importa la igualdad solo como concepto o idea, sino su impacto en la vida de educadoras, educadores, educandas y educandos. En este sentido, no importa solo pensar o postular la igualdad, sino, sobre todo, vivirla en las prácticas educativas.

Sin embargo, como decíamos, la igualdad es desmentida en el tejido de la vida social. En nuestras sociedades, algunos están arriba y otros abajo, algunos pueden mucho más que otros, por lo menos en determinados sentidos, como el social, el cultural y el económico: el capitalismo vive de inferiores y superiores. También las instituciones escolares desmienten aquella igualdad: muchos ni siquiera consiguen entrar en ellas, o son expulsados enseguida; otros pasan por ellas con éxito, desde el inicio hasta el final, en la edad oportuna algunos, mucho más rápidamente que otros.

Así las cosas, ¿qué significa afirmar que todos (todas) somos iguales o que nadie es desigual como principio de una política afirmada en la educación? ¿En qué sentido es posible la igualdad como principio de una política para la educación, cuando nuestras sociedades -y sus instituciones educativas- viven de desigualdad? ¿Sería una afirmación romántica, idealista? ¿La igualdad puede ser pedagógicamente practicada en una realidad cargada de desigualdades como la nuestra? ¿En qué sentido?

El principio de igualdad significa, por un lado, que, en la relación pedagógica, las desigualdades sociales están suspendidas o interrumpidas (Masschelein; Simons, 2014). Eso significa que, quien enseña y quien aprende se posicionan como iguales en tanto participantes de esa relación de enseñanza y aprendizaje. Cuando la relación pedagógica se inscribe en una política institucional que imposibilita o inviabiliza la efectiva afirmación de la igualdad, no hay educación deseable. Si un educador o educadora no consigue interrumpir la lógica de la desigualdad, inevitablemente enseñará lo que la institución presupone: su lugar de superioridad o el lugar de inferioridad del educando. Puede enseñar las teorías más emancipadoras e interesantes, pero lo que los estudiantes aprenderán y vivirán es la lógica desigual de la relación, más allá de los contenidos que son transmitidos.

En este sentido, la afirmación de igualdad es relativamente "simple". Solo depende de una decisión (corporal, existencial, no solo intelectual) de quien ocupa la posición educadora y de una práctica coherente con esa decisión. Puede estar presente en los contextos institucionales más diversos, de los menos a los más autoritarios, en los cuales siempre hay fisuras, grietas, agujeros que permiten interrumpir las prácticas no igualitarias. He aquí que la dimensión política del educador encuentra proyección y sentido profundos, inclusive cuando el contexto de la macropolítica educativa resulta más conservador y autoritario.

Por otro lado, ese carácter político se vincula con la dimensión pública de la escuela (Masschelein; Simons, 2014; Rodríguez, 2001). La escuela es pública no por ser administrada por el Estado o a causa de no serlo por una organización privada; es pública porque es de y para todos, en el sentido de poder ser igualmente habitada por cualquiera y de constituirse en un espacio en donde las desigualdades entre sus habitantes quedan suspendidas, interrumpidas en el momento en que todos y cualquiera la habitan.

En este sentido, la tradición de la escuela popular latinoamericana afirma un carácter radical de la escuela pública que solo puede ser al mismo tiempo social, general y popular (Rodríguez, 2016, p. 26; ver también Durán y Kohan, 2018). Una escuela no es verdaderamente pública cuando sus exigencias desigualan a los iguales, cuando expulsa en lugar de acoger, o cuando una parte de sus estudiantes puede más que otra al reproducir, en las relaciones pedagógicas, algún criterio socialmente imperante.

Que la igualdad sea una condición de la institución y de las relaciones pedagógicas no significa que educadores y estudiantes sepan las mismas cosas o que no existan saberes del educador que los estudiantes pueden aprender (así como hay saberes estudiantiles que los educadores también pueden aprender). Claro que educadores y educadoras saben muchas cosas que estudiantes no saben, y por eso llegaron a ocupar los lugares institucionales que ocupan, en particular, en sociedades como las nuestras, que regulan las posiciones 
institucionales en función de los saberes de quienes aspiran a ocupar esas posiciones. Pero esas condiciones no los convierten en superiores. Desarrollaron más una igual capacidad de aprender, pensar y saber. Son superiores debido a una educación estructurada según una lógica jerárquica.

\section{OTRO DEFENSOR DE LA IGUALDAD: JoSEPH JACOTOT}

Entre los que tratan la igualdad como condición o principio político para la educación, se destaca el pedagogo francés del siglo XIX Joseph Jacotot (1770-1840), creador de la enseñanza universal, también llamada filosofía panecástica, popularizada en nuestro tiempo por Jacques Rancière (2013). La enseñanza universal consiste justamente en la afirmación del principio de que todas las inteligencias son iguales y en la postulación de la libertad como método para enseñar y para aprender, a favor de la emancipación intelectual de los estudiantes.

Para Jacotot, el principio de igualdad de las inteligencia no es una verdad científica comprobada, sino una opinión a ser verificada. Esa opinión es una fe, una creencia política en favor de la emancipación de los pobres que se fundamenta en una de autores como Descartes, Locke y Newton, y justifica las obvias desigualdades intelectuales que se perciben en el mundo social no por alguna desigualdad intelectual natural, sino por los diferentes estímulos que sus inteligencias reciben en su educación.

Por eso, para Jacotot, solo es posible una educación emancipadora a partir del principio de igualdad de las inteligencias: cuando se parte del principio de que todos los seres humanos son intelectualmente iguales. El maestro o la maestra que desconsidera ese principio y se coloca arriba de sus alumnos fatalmente los embrutece, y también se embrutece a sí mismo, lo que lleva a una conversación insignificante con quien reconoce como inferiores. Sus alumnos aprenderán e interiorizarán esa jerarquía intelectual que el maestro presupone y transmite. Al contrario, un maestro o maestra emancipadora transmite la igualdad de las inteligencias, lo único que es preciso transmitir para emancipar a alguien: la confianza en su capacidad intelectual.

Cuando la enseñanza universal funciona, una maestra emancipadora ignora lo que enseña, no sabe lo que un alumno o alumna aprende. Es solo una compañera de viaje que hace el camino del aprendizaje con su alumna cuidando que aprenda con atención, procurando que su voluntad no deje nunca de confiar en su propia capacidad intelectual. Hay dos niveles de ignorancia afirmados por quien sigue la enseñanza universal: ignora lo que su alumno aprende y, sobre todo, ignora la desigualdad de las inteligencias que toda institución escolar presupone, y sobre la que se funda. He aquí el sentido más profundo de su ignorancia: un rechazo, la no aceptación de un orden embrutecedor.

En la enseñanza universal, no hay método para enseñar ni para aprender. El método es de cada quién. La libertad del maestro o maestra para enseñar hace a la libertad del alumno o alumna para aprender. Quien aprende libremente piensa y vive libremente. En carta de 1828 al general La Fayette, Jacotot responde al interés surgido en los Estados Unidos por su forma de practicar la educación en los siguientes términos:

Todo hombre que es enseñando no es más que la mitad de hombre. En todas partes donde hay escolares, hay maestros. Cuando la inteligencia no es libre, no veo qué podría serlo. Aviso a los Americanos. Se puede ser independiente sin ser libre; la independencia es relativa, la libertad es absoluta. Soy independiente cuando no tengo maestro, es el hecho de otro; soy libre cuando no quiero un maestro, es mi hecho. Para que esta voluntad sea firme, estable, invariable, hay que sentir sus fuerzas, todas sus fuerzas, no solamente morales, sino intelectuales (Jacotot apud Vermeren, 2017, p. 220-221).

Este pasaje recuerda el "nadie educa a nadie" de Pedagogía del oprimido, de Paulo Freire (1970, p. 70). En ambos, se afirma la libertad de quien aprende. En ese caso, Jacotot afirma el valor absoluto de la libertad, emanada de la confianza en la propia capacidad intelectual; es libre quien se considera intelectualmente igual a cualquiera. No hay libertad cuando hay superiores e inferiores. La cuestión no es solo que el maestro o maestra no se coloque como superior. Quien aprende debe colocarse como un igual. En una relación de opresión, 
opresor y oprimidos son oprimidos, porque es la relación establecida entre ellos que oprime. Quien es libre no quiere un maestro o maestra embrutecedora, porque su voluntad confía en la propia capacidad intelectual. Para no querer tal maestro es preciso sentir la potencia de la propia capacidad intelectual.

¿Eso significa que, para Jacotot, no precisamos de maestros o maestras? Claro que no. Jacotot parece decir que una persona emancipada no quiere un maestro o maestra explicadora o embrutecedora. No precisamos de maestros embrutecedores, sino maestros emancipadores tanto para la emancipación de las personas embrutecidas como para la relación pedagógica entre personas emancipadas. Para la emancipación de las inteligencias, se necesita, entonces, maestros y maestras que ayuden a todas las personas a encontrar confianza en la propia capacidad, y que acompañen, en su proceso de aprendizaje, a las personas que ya tengan esa confianza.

\section{Notas históRICAS DE LA ENSEÑANZA UNIVERSAL EN BRASIL}

Las enseñanzas de Jacotot llegaron a Brasil, el 3 de mayo de 1847, cuando fue fundado el Instituto Panecástico do Brasil. Tenía como objetivo "propagar los principios de la emancipación intelectual del inmortal Jacotot, y substituir a la autoridad y al pedantismo de los derechos de la razón humana” (Sciencia, 1847, v.1, n.3, p. 57). ${ }^{2}$ Uno de sus impulsores fue el homeópata francés Benoît Jules Mure, que dejó testimonio de lo que llamó el "gran principio de Jacotot": "Dios creó el alma humana capaz de instruirse a sí misma, y sin el concurso de maestros explicadores" y de la máxima que orienta el trabajo intelectual: "Quien quiere puede" (Sciencia, 1848 , v.2, n.18, p. 209). ¿Qué quiere decir? Precisamente que quien quiere puede, pero como no todo el mundo quiere -y el mundo social parece hacer mucho para que algunas personas no quieran-, allí encuentra sentido la tarea de un maestro o maestra preocupada con una educación para la emancipación intelectual: trabajar sobre la voluntad de los que fueron enseñados, por la sociedad desigual, a no confiar en su propia capacidad para que confíen en ella.

Mure propuso, a partir del Instituto Panecástico do Brasil, un "Plan de Universidad para Brasil”, destinado a eliminar los principios monárquico y católico, a emancipar las inteligencias y llevar a Brasil al "mayor auge del saber y de la ilustración” (Sciencia, 1847, v.1, n. 5, p. 82). ${ }^{3}$ Tanto el plan como una mirada pesimista sobre su posible éxito en Brasil son presentados en la revista Sciencia, en la que también escribe E. J. Ackermann, otro de los que intentaron llevar las ideas de Jacotot a Brasil. Esos estudios destacan las virtudes del método universal (que no es un método, porque los procesos de aprendizaje no son prescriptos, sino dependientes del libre arbitrio de cada quien) de la siguiente manera:

Este método no ofrece sólo la ventaja de abreviar considerablemente el tiempo de instrucción y de tornarla más provechosa; sin embargo, facilitando a todo padre de familia hacer aprender a sus hijos aquello que él mismo ignora, establece entre los hombres una verdadera igualdad. Es esto que debe grabar el nombre de Jacotot en el corazón de todos los verdaderos amigos de la humanidad. La enseñanza universal es el método del pobre (Sciencia, 1848, v.2, n.16, p. 195).

Como vemos, el método no metódico ofrece ventajas pedagógicas. Permite reducir el tiempo de instrucción y también que alumnos y alumnas quieran aprender y no se sientan obligados a hacerlo, como habitualmente sucede. Ackermann también deja ver el valor político de la enseñanza de Jacotot: sirve, sobre todo, al pueblo, a una educación popular: un padre o una madre analfabeto(a) puede alfabetizar, educar y emancipar a sus hijos. Con él, hijos de pobres y analfabetos pueden aprender con sus padres y madres lo que estos ignoran. Un padre o una madre ricos pueden pagar un maestro, una escuela para sus hijos. Un padre o una madre pobres no pueden hacerlo pero pueden, ellos mismos, por la enseñanza universal, emancipar a sus hijos. Para eso, sólo es preciso que ellos mismos estén emancipados. ${ }^{4}$ Así, la enseñanza universal permite que las personas pobres superen las limitaciones propias de su condición y puedan actualizar la potencia de la que su inteligencia es capaz. La enseñanza universal es, por lo tanto, revolucionaria, lo que, ciertamente, es una de las razones de que no haya triunfado en Brasil. 


\section{Joseph Jacotot y Paulo Freire}

A pesar de las evidentes diferencias entre alguien que vivió en la Francia posrevolucionaria, durante el siglo XIX, y quien vivió en Brasil durante el siglo XX, hay semejanzas significativas en la manera en cómo Jacotot y Freire pensaron y vivieron la educación. Paulo Freire se inscribe en la tradición de los que viven una vida filosófica y pedagógica (Kohan, 2018). Joseph Jacotot también: con el retorno de la monarquía de los Borbones, deja Francia para enseñar en Lovaina, en los Países Bajos. Si bien no es directamente forzado a dejar su país, la política lo hace salir. Ambos viven, debido a sus vidas comprometidas, la experiencia del exilio. Para los dos, el exilio -más o menos forzado- es un acto político que contribuye decisivamente para sus descubrimientos y prácticas educativas, sus apuestas filosóficas, y también para los efectos políticos de esos descubrimientos entre los sectores populares. Paulo Freire vive la dificultad y la dureza del exilio como una experiencia positiva en su trayectoria. El soñador de Pernambuco consigue valorizar el exilio y lo caracteriza como un "fondeadero", un remanso que lo ayudó a "unir recuerdos, reconocer hechos, actos, gestos, unir conocimientos, soldar momentos, reconocer para conocer mejor” (2010 [1992], p. 36). Dio tanta importancia al exilio en su vida, que dijo haber pasado no solo por uno sino por tres: un primero, en el útero de la madre, durante el tiempo de gestación; un segundo, en el período en que su familia, por causa de la crisis económica, se muda de Recife para Jaboatão dos Guararapes; y finalmente, un tercero, en el exterior -en Bolivia, Chile, Estados Unidos y Suiza-, impuesto por la dictadura de 1964 (Freire, 2013 [2000], p. 60).

Jacotot y Freire son marcados por una experiencia vital relacionada al enseñar/aprender (la alfabetización familiar, en un caso, y la enseñanza en una universidad extranjera, en el otro), y los dos dedican sus vidas a otorgar sentido y desplegar los significados que pueden desprenderse de esas experiencias impactantes. En ambos, la lengua extranjera desempeña también un papel central. Para Jacotot, es decisiva para descubrir el principio de igualdad de las inteligencias justamente a partir de una experiencia en la que él, ya exiliado en Lovaina, ya no puede hablar su lengua materna (francés) con estudiantes que hablan otra lengua (holandés). Así, por el exilio y la experiencia de extranjeridad debe salir del cómodo papel de profesor explicador. La imposibilidad de seguir explicando en su lengua sus saberes de literatura lo hace descubrir los secretos de la emancipación intelectual. Eso no habría sido posible sin confrontarse con la lengua extranjera de sus estudiantes holandeses.

Paulo Freire también tuvo que exiliarse, forzosamente, más de una vez, como acabamos de ver. La más brutal fue, sin dudas, después del Golpe Militar de 1964 en Brasil, cuando se exilia primero en Bolivia. Paulo Freire sale de la embajada de Bolivia en Río de Janeiro con trabajo asegurado en La Paz. Al inicio, la pasa mal con la altitud, pero después de quince días, ya acostumbrado, tiene que ir para Chile por causa de un nuevo golpe de Estado, esta vez en Bolivia (Freire; Guimarães, 2010 [1987], p. 79). Así, el pensamiento principal de Paulo Freire a respecto de la emancipación, su libro más emblemático, Pedagogía del oprimido, solo puede ser publicado por primera vez en inglés, en 1970 (Nueva York: Herder and Herder), sin el prefacio de Ernani María Fiori, pero con la presentación de Richard Shaull y un prefacio del propio Freire. En ese mismo año, el libro fue también publicado en castellano (Montevideo: Tierra Nueva), con el prefacio de Ernani, y sólo algunos años después, se publicó en portugués (São Paulo: Paz e Terra). ${ }^{5}$ No se puede afirmar que haya sido necesitado escuchar una lengua extranjera para impulsar su pensamiento. Sin embargo, como consecuencia de sus condiciones de trabajo, de tener que vivir en otros países, Freire precisó traducirse a sí mismo, expresar y comunicar en lenguas extranjeras sus ideas al respecto de la emancipación. Y, según su propio entendimiento, el exilio fue decisivo tanto para repensar la realidad de Brasil como para desarrollar su pedagogía y su comprensión sobre la dimensión política de la educación (Freire; Shor, 2014 [1986 ], p. 57). De modo que las lenguas extranjeras desempeñaron un papel principal en los pensamientos, en las escrituras y en las vidas de Freire y Jacotot.

Otra coincidencia notable es que ambos son comúnmente asociados a métodos: Jacotot, al método universal, Freire, a un método para la alfabetización de jóvenes y adultos. No obstante, para ninguno 
de ellos existe, de hecho, algo así como un método, o, dicho más radicalmente, el método no es una de las cuestiones educativas más relevantes, sino el sentido político que cualquier método despliega. Para ninguno de ellos los métodos son decisivos. Para Jacotot, el método es el del alumno (Rancière, 2013). Para Freire, la transformación propiciada por una educación liberadora no es una cuestión de método, sino del "establecimiento de una relación diferente con el conocimiento y la sociedad" (Freire; Shor, 2014 [1986], p. 63). O entonces, más explícita y detalladamente:

De ahí que jamás nos hayamos detenido en el estudio de los métodos y técnicas de alfabetización de adultos en cuanto tales, y en cambio, hayamos considerado esos métodos y técnicas como algo que está al servicio de (y en coherencia con) una determinada teoría del conocimiento puesta en práctica -la cual, a su vez, tiene que ser fiel a una determinada opción política. En este sentido, si la opción del educador es revolucionaria, y si su práctica es coherente con su opción, la alfabetización de adultos, como acto de conocimiento, tiene en el alfabetizando uno de los sujetos de dicho acto. Así, lo que se le plantea a tal educador es la búsqueda de los mejores caminos, de las mejores ayudas que hagan posible que el alfabetizando ejerza su papel de sujeto de conocimiento en el proceso de su alfabetización. El educador tiene que ser un inventor y un reinventor constante de todos aquellos medios y de todos aquellos caminos que faciliten más y más la problematización del objeto que ha de ser descubierto y finalmente aprehendido por los educandos (Freire, 2007 [1977], p. 18).

No hay un método determinado para el educador revolucionario. Antes, hay un compromiso con una política revolucionaria, que exige una práctica educadora consistente con ese compromiso: afirmar la igual potencia inventiva de los seres humanos que torna al educador capaz de posibilitar algunos caminos para una educación emancipadora.

En una entrevista de la época de la publicación de la primera edición brasileña de El maestro ignorante, Rancière traza otro punto fuerte en común entre los dos autores: el compromiso político con la emancipación/liberación del pueblo. Ambos estarían enfrentando el lema positivista pedagógico de "Orden y Progreso", inscripto en la bandera de Brasil, los dos interrumpiendo e interpelando la supuesta armonía entre el orden del saber y el orden social. O sea, uno y otro son críticos respecto del papel del orden pedagógico instituido en términos de un orden más justo, a favor de los excluidos y excluidas. Los dos sospechan del orden y del progreso que podrían venir de los poderes instaurados. Dicho de otra manera, son escépticos con respecto al orden pedagógico instituido por las repúblicas positivistas y afirman la necesidad de intervenir en ellas para interrumpir sus efectos excluyentes y producir efectos emancipadores.

En cuanto a las principales diferencias entre Jacotot y Freire, en esa misma entrevista, para Rancière, no hay nada más alejado de Jacotot que un método para la "concientización" social. A diferencia de Paulo Freire, Jacotot afirma que la igualdad solo se puede dar de individuo a individuo, y que es imposible de ser institucionalizada o propagada como forma de emancipación social. No obstante, como vimos, aunque la emancipación intelectual solo sea posible de forma individual, no hay emancipación social que no presuponga una emancipación individual. En ese sentido, se podría aproximar el anarquismo pesimista de Jacotot al progresismo optimista de Paulo Freire; como Rancière sugiere, "en el proceso de emancipación intelectual como vector de movimientos de emancipación política que rompen con una lógica social, una lógica institucional" (Vermeren; Cornu; Benvenuto, 2003, p. 199). El propio Paulo Freire sugiere algo en ese sentido, al mismo tiempo que propone una crítica implícita a una emancipación meramente intelectual e individual, como la de Jacotot. En un libro hablado con Ira Shor, afirma no creer en la liberación o emancipación individual, y se muestra receloso de cualquier sentimiento individual y no social de libertad. No obstante, igual que Jacotot, considera la primera una condición necesaria de la segunda. En palabras de Freire:

\footnotetext{
Mientras que el empowerment individual o el empowerment de algunos alumnos, o la sensación de haber cambiado, no es suficiente en lo que respecta a la transformación de la sociedad como un todo, es absolutamente necesario para el proceso de transformación social. ¿Está claro? El desarrollo crítico de estos alumnos es fundamental para la transformación radical de la sociedad. Su curiosidad, su percepción crítica de la realidad son fundamentales para la transformación social, pero no son suficientes (Freire; Shor, 2014 [1986], p. 174-175, cursiva en el original).
} 
Más claro, imposible. Mientras Jacotot defiende la emancipación individual y afirma que solo ella es posible, sus experiencias vitales fueron tornándolo cada vez más pesimista en cuanto a su proyección social. En cambio, Paulo Freire, aunque también encuentra enormes dificultades para poner sus ideas en práctica, jamás dejó de pensar que la emancipación social de los oprimidos y oprimidas era el sentido principal de una vida educadora. Sin esa proyección social, la emancipación tendría poco valor. Más aún: la emancipación "final" que interesa a Paulo Freire no es solo intelectual o cognitiva, sino también económica, social y política, con toda las complejidades y dificultades que supone la relación entre educación y sociedad.

La concientización no es un tema simple. Hasta Paulo Freire dejó de usar ese término temiendo ser mal entendido. El punto central, en cualquier caso, es saber si quien ocupa la posición educadora posee una conciencia más plena o crítica que el educando no posee, algo que debería ser incorporado a través de la relación pedagógica (si así fuera, no parecería muy emancipadora la relación), y hasta donde quien educa conduce a quien es educado a un lugar que aquel ya conoce o si solo contribuye a una forma de conciencia que no está en él anticipar o controlar.

En palabras más simples: ¿quien educa ya sabe la conciencia que un educando debe alcanzar? Si la respuesta a esa pregunta fuera afirmativa, el valor y los sentidos de la emancipación quedarían afectados. Si pensamos que existe un saber histórico determinado - por ejemplo, el materialismo histórico-, que es, de alguna forma, un a priori de la relación pedagógica, independientemente del saber de educadoras, educadores, educandos y educandas, de esa lógica se desprenden consecuencias políticas poco propicias para la relación pedagógica. En otras palabras, si quien educa ya sabe el saber qué es preciso conocer para la emancipación de quien está siendo educado, podríamos poner en cuestión si de hecho lo está emancipando. En un libro reciente, el actual director del Instituto Paulo Freire, Moacir Gadotti, asimila la concientización a la igualdad de las inteligencias como un principio que permitiría a cada uno decir su palabra (Gadotti; Carnoy, 2018).

Paulo Freire parece haber oscilado en relación con esa cuestión. Por ejemplo, en el libro hablado con Ira Shor, afirma que la tarea de un educador liberador es "dirigir un estudio serio sobre algún objeto, en el que los alumnos reflexionan sobre la intimidad de la existencia de ese objeto” (Freire; Shor, 2014 [1986], p. 261). Allí, llama a esa posición de "radical democrática", porque apuesta al mismo tiempo a la libertad y no renuncia a asumir la directividad docente, sin por eso negar la autonomía de los alumnos, en tanto confía en su capacidad de reflexión. El trabajo concientizador del educador no refiere a la transmisión de un saber liberador, sino al estímulo de la reflexibilidad del alumno para que pueda "descubrir la manipulación y los mitos de la sociedad", según Freire afirma en el párrafo siguiente. Claro que, aun en ese caso, si la manipulación y los mitos de la sociedad son ya conocidos de antemano por el educador y sólo pueden ser explicitados en términos de ciertas categorías o marcos teóricos (que la terminología empleada por Freire parece presuponer), podríamos cuestionar en qué medida se confía de hecho en la igual capacidad de educadores y educandos.

En sus últimos trabajos, Paulo Freire prefiere utilizar menos la idea de concientización porque considera que genera excesiva polémica e interpretaciones dudosas. De un modo más general, las certezas en los escritos de Paulo Freire disminuyen gradualmente, y en el final de su obra parecen estar más próximas de algunos principios relacionales, como la igualdad, y menos situadas en teorías explicativas de la realidad, como ocurría al inicio de sus escritos.

Finalmente, podemos retomar nuestra preocupación primera y el punto de conexión entre Jacotot y Freire, en la medida en que ambos afirman la igualdad como un principio no solo en sus pensamiento y escritos, sino también en su vida. Veamos cómo eso se manifiesta. Algunas anécdotas sobre Jacotot lo retratan, por ejemplo, en la manera como recibe a un emisario llegado de París a Lovaina, enviado por la Sociedad de Métodos de París para conocer su propuesta: "Antes de entrar en materia, declaro que no veo en usted más que un curioso; por lo tanto, lo pongo en cuarta línea. Si viniera un pobre, un campesino, un padre de familia, él pasaría antes que usted" (Vermeren, 2017, p. 211). Ese relato muestra que Jacotot vivía la igualdad que afirmaba y en la cual creía. De forma semejante, Paulo Freire relata varias situaciones en que se puede constatar ese mismo sentimiento vital de igualdad. Por ejemplo, al referirse a unas conferencias que dicta en la época de su trabajo 
en el SESI, en Recife, narra un momento en que, después de hablar sobre Piaget, un operario le da lo que él llama una "lección de clase", mostrando cómo su discurso académico es propio de alguien de otra clase social que está muy lejos de la clase de los que lo escuchan. Frente a esta intervención, ante el saber de clase aprendido, Freire (2010 [1992], p. 44) afirma: "Ese discurso fue pronunciado hace cerca de 32 años. Jamás lo olvidé". Eso indica cómo siempre apreciaba vivir la igualdad -palabra usada en el próximo fragmento, en que comenta el gran impacto de situaciones vividas como esa en toda su trayectoria pedagógica posterior:

[...] casi siempre, en las ceremonias académicas en que me torno doctor honoris causa de alguna universidad, reconozco cuánto debo también a los hombres como éste del que hablo ahora, y no sólo a científicos, pensadores y pensadoras que igualmente me enseñaron y continúan enseñándome y sin los cuales y las cuales no me habría sido posible aprender, inclusive del obrero de aquella noche" (p. 42-43, cursiva mía).

En varios libros, Paulo Freire narra situaciones muy semejantes en diversos lugares del mundo. Un operario u operaria es un pensador o pensadora igual a cualquier científico, que enseña tanto y tal vez más, en la medida en que, como en la situación narrada, enseña un saber de vida atravesado por una condición política que no se puede aprender en un claustro académico. No enseña más quien la sociedad legitima como transmisor oficial de saberes, sino quien sabe los saberes de la vida porque los vive. Operaries no enseñan un saber institucionalizado, sino un saber para la vida en común. Son saberes indisolublemente ligados a la existencia colectiva, que muestran su verdad, sus secretos; son capacidades intelectuales que aquellas mismas instituciones repetidamente disfrazan o inferiorizan.

\section{LA IGUALDAD EN EDUCACIÓN}

Podríamos afirmar, entonces, inspirados en Joseph Jacotot y Paulo Freire, que la igualdad es un principio importante y transversal para una política deseable de la relación pedagógica. Esa igualdad, afirmada como principio o inicio -no como meta u objetivo-, atraviesa diversos campos: la vida y la capacidad intelectual, pero también los saberes y los no saberes, el pensamiento, los afectos. La cuestión del saber es crucial para Paulo Freire: se suele confundir la igualdad de los saberes con el vaciamiento de la función pedagógica. Al contrario, la igualdad política significa que los saberes docentes y estudiantiles no se jerarquizan por las posiciones de poder que cada uno ocupa. Ellos pueden tener valor y sentido epistemológico o estético distintos, pero eso nada tiene que ver con quiénes son sus portadores: ciertos saberes no tienen más legitimidad que otros debido al lugar de poder que ocupa quien los afirma en la relación pedagógica.

En sociedades absurdamente desiguales como las nuestras, existen efectos políticos desiguales fuera de la relación pedagógica, pero no dentro de ella. Docentes y estudiantes, en cuanto tales, no tienen más (o menos) poder, por lo que saben o dejan de saber. He aquí la enseñanza de Paulo Freire: para enseñar y aprender de una forma dialógica, todos los saberes merecen ser oídos e igualmente atendidos, puestos en diálogo en un mismo nivel, más allá de quien los expresa. Es juntamente en ese diálogo que un educador enseña y aprende, reconstruyendo sus propios saberes a partir de los saberes de sus educandos.

Para Paulo Freire, la necesidad de postular la igualdad nace de la constatación de las diferencias entre todas las formas de vida. Lo deja claro, por ejemplo, con una referencia a J. François en Pedagogía de la esperanza:

Nosotros somos todos diferentes y el modo como se reproducen los seres vivos está programado para que lo seamos. Por eso el hombre tuvo necesidad, un día, de fabricar el concepto de igualdad. Si fuéramos todos idénticos, como una población de bacterias, la idea de igualdad sería perfectamente inútil. (Freire, 2010 [1992], p. 124).

Si no fuéramos diferentes, la igualdad sería innecesaria. Pero nuestras sociedades han hecho de las diferencias, desigualdades. Es la desigualdad la que se opone a la igualdad, no la diferencia. Son las desigualdades las que inhiben una relación pedagógica dialógica, no las diferencias -que, al contrario, la alimentan, la potencian, cuando se asientan en la igualdad. 
Paulo Freire enfatiza la cuestión del saber en una perspectiva emancipadora de la educación. Si colocamos el pensar en ese lugar, entonces gana fuerza, inspirada en Jacotot, la afirmación de la igual capacidad de pensar de todos los seres humanos como principio. De tal forma, afirmar, como principio, una concepción igualitaria de la capacidad de pensar de educadoras, educadores, educandas y educandos pasa a ser una condición política necesaria para que los participantes de esa práctica educativa puedan, coherentemente, desplegar la igual potencia problematizadora de que son capaces para poner en cuestión su vida, y el mundo en que viven.

\section{REFERENCIAS}

Albuquerque, S. (2019). Filosofia panecástica de Jacotot nos periódicos brasileiros oitocentista (1847-1848). En S. Albuquerque; E. Silva; I. Santos (Orgs.). A história da Educação em manuscritos, periódicos e compêndios do XIX e XX (p. 78-96.). Rio de Janeiro: EdUERJ.

Andreola, B. A. (2001). Pedagogia do oprimido: um projeto coletivo. En A. M. Araújo Freire (Org.). A pedagogia da libertação em Paulo Freire (p. 43-46). São Paulo: Unesp.

Brandão, C. (2015). Paulo Freire A educação, a cultura e a universidade: memória de uma história há cinqüenta anos atrás. Revista Festim. Natal, RN, 1 (2), 157-172.

Brugaletta, F. (2019). La circulación de la pedagogía de Paulo Freire. El papel de las editoriales en la historia reciente de la educación. En M. E. Aguirre Lora (comp). Desplazamientos. Educación, historia, cultura. México, ISSUE.

Casali, A. (2001). A Pedagogia do oprimido: clandestina e universal. En A. M. Araújo Freire (org.). A pedagogia da libertação em Paulo Freire (p. 17-22). São Paulo: Paz e Terra.

Durán, M.; Kohan, W. (2018). Manifesto por uma escola filosófica popular. Rio de Janeiro: NEFI.

Freire P. (2007) [1977]. Cartas a Guinea-Bissau. Apuntes de una experiencia pedagógica en proceso. 12. ed. México: Siglo XXI Editores.

Freire, P. (2008) [1996]. Pedagogía de la autonomía. Saberes necesarios para la práctica educativa. 2. ed. Buenos Aires: Siglo XXI Editores Argentina.

Freire, P. (2010) [1992]. Pedagogía de la Esperanza. Un reencuentro con la Pedagogía del Oprimido. 2. ed. Buenos Aires: Siglo XXI Editores Argentina.

Freire, P. (2013) [2000]. Pedagogía de la indignación. Castas pedagógicas en un mundo revuelto. 1. ed. Buenos Aires: Siglo XXI Editores Argentina.

Freire, P; Guimarães, S. (2010) [1987]. Aprendendo com a própria história. 3. ed. rev. e ampl. São Paulo: Paz e Terra.

Freire, P.; Shor, I. (2014) [1986]. Miedo y osadia: La cotidianeidad del docente que se arriesga a practicar una pedagogía transformadora. 1. ed. Buenos Aires: Siglo XXI Editores Argentina.

Gadotti, M.; Carnoy, M. (2008). (orgs.). Reinventando Paulo Freire. A práxis do Instituto Paulo Freire. São Paulo: Instituto Paulo Freire; Lamann Center; Stanford Graduate School of Education.

Kohan, W. (2018). Paulo Freire, a filosofia e a vida. Revista Educação Online (29), p. 90-112.

Masschelein, J.; Simons, M. (2014). En defensa de la escuela. Una cuestión pública. 1. ed. Buenos Aires: Miño y Dávila.

Rancière, J. (2013). El maestro ignorante. Cinco lecciones sobre la emancipación intelectual. Buenos Aires: Libros del Zorzal.

Rodríguez, L. M.; Marin, C.; Moreno, S. M.; Rubano, M. del C. (2007). Paulo Freire: una pedagogía desde América Latina. Ciencia, Docencia y Tecnología, Paraná, XVIII (34), 129-171.

Rodríguez, L. (2015). Paulo Freire. Una biografía intelectual. Surgimiento y maduración de la pedagogía del oprimido. Buenos Aires: Colihue.

Rodríguez, S. (2001). Obras Completas - v. I y II. Caracas: República Bolivariana de Venezuela.

Rodríguez, S. (2016). Inventamos o erramos. Apresentação, tradução e notas de M. Durán y W. Kohan. Belo Horizonte: Autêntica. 
SCIENCIA - Revista Synthetica dos Conhecimentos Humanos, Rio de Janeiro, v.1, n. 3. Setembro, 1847, p. 57. Disponible en: <http://memoria.bn.br/docreader/730076/59>. Acceso el: 27 de agosto 2019.

SCIENCIA - Revista Synthetica dos Conhecimentos Humanos, Rio de Janeiro, v.1, n. 5. Setembro, 1847, p. 82. Disponible en: < http://memoria.bn.br/docreader/730076/84>. Acceso el: 27 de agosto 2019.

SCIENCIA - Revista Synthetica dos Conhecimentos Humanos, Rio de Janeiro, v.2, n. 16. Setembro, 1848, p. 195. Disponible en:<http://memoria.bn.br/docreader/730076/197>. Acceso el: 27 de agosto 2019.

SCIENCIA - Revista Synthetica dos Conhecimentos Humanos, Rio de Janeiro, v.2, n. 18. Setembro, 1848, p. 209. Disponible en:<http://memoria.bn.br/docreader/730076/211>. Acceso el: 27 de agosto 2019.

Vermeren, P. (2017). Nada está en nada. O todo el mundo sabe la lógica. El método de enseñanza universal de Joseph Jacotot y la emancipación intelectual en las clases pobres. Hermenéutica Intercultural, (28), p. 211-227.

Vermeren, P.; Cornu, L.; Benvenuto, A. (2003). Atualidade de O mestre ignorante. Dossiê: "Igualdade e liberdade em educação. A propósito de O mestre ignorante.". Organizadores: Jorge Larrosa e Walter Kohan, Educação \& Sociedade, 24 (82), p. 185-202.

\section{Notas}

1 Mantenemos la palabra del original. En este texto tratamos de ser sensibles a una gramática no machista.

2 Suzana Lopes de Albuquerque (2019) trabajó sobre las fuentes que comprueban la circulación de las ideas de Jacotot en Brasil: cartas de Castilho y el periódico de homeopatía Sciencia, digitalizado y disponible en el página web de la Hemeroteca Digital de la Biblioteca Nacional con sus 25 ediciones, siendo 5 de 1847 y las demás de 1848.

3 Sabemos también que el primer director de la Escuela Normal de Niterói, José da Costa Azevedo, fue responsable de la elaboración de un método de lectura basado en las ideas de Jacotot (Albuquerque, 2019).

4 Las ideas de Jacotot podrían ser apropiadas por discursos conservadores como una "salida” o "solución” para el forzado y decidido desguace de la escuela pública: la enseñanza domiciliaria sería una forma de superación de los problemas institucionales de esa escuela, que estaría generando gastos innecesarios y mal aprovechados a las arcas públicas. Sin embargo, esa "salida", que retiraría del Estado la responsabilidad por la educación para delegarla a las familias o a las iglesias evangélicas de las comunidades más pobres, es de hecho incompatible con los principios y el sentido de la enseñanza universal de Jacotot.

5 Cf. "Nota sobre as edições da Pedagogia do oprimido", en la edición conmemorativa de los cincuenta años (Freire, 2018, p. 25-26). Al respecto, hay una discrepancia observada por los editores (Freire, 2018, p. 25, n. 16) de esa versión (examinada en ejemplares de la primera edición) con la del propio Paulo Freire en Pedagogía de la Esperanza (2010 [1992]), en la cual él afirma que la primera edición en portugués habría sido publicada en Brasil en 1975. Los editores agregan que Paulo Freire debe haber recibido esa información del editor de Paz e Terra y que, como ambos ya fallecieron, la cuestión no podrá ser resuelta. Para un estudio más pormenorizado de las ediciones de Pedagogia do Oprimido, véase: Brugaletta (2019).

\section{BY-NC-SA}

